\title{
Application of holistic nursing in care for cranial neurointervention.
}

\author{
Haijuan Lu* \\ Department of Nursing, Nanyang Central Hospital, Nanyang City, PR China
}

\begin{abstract}
Objective: To explore the application and clinical value of holistic nursing in care for cranial neurointervention.

Methods: A total of 138 patients needed the treatment of cranial neurointervention, who were admitted in dept. of neurosurgery in our hospital from August 2015 to January 2016, were divided into routine nursing group (control group) and holistic nursing group (observation group), 69 patients a group. After treatment and nursing, the improvement of life quality, occurrence of complications, average hospitalization expenses and length of stay, as well as patient satisfaction were compared and analyzed.

Results: After treatment and nursing, in the observation group, the improvement of life quality was better significantly than the control group $(t=7.03, P=0.00)$, the occurrence of complication lower obviously than the control group $\left(\chi^{2}=12.64, P=0.00\right)$; the average length of stay was less distinctly than the control group $(t=2.85, P=0.04)$, the average hospitalization expenses less significantly than the control group $(\mathrm{t}=\mathbf{2 9 . 6 4}, \mathrm{P}=\mathbf{0 . 0 0})$; and patient satisfaction was much higher than the control group $\left(\chi^{2}=16.23, P=0.00\right)$.

Conclusion: In the course of nursing for cranial neurointervention, giving holistic nursing is able to prevent complications, improve patients' quality of life, decrease their economic burden, and increase their satisfaction. Holistic Nursing Care for Cranial neurointerventional must become habitual Nursing Care for Cranial neurointerventional.
\end{abstract}

Keywords: Holistic nursing, Cranial neurointervention, Complications, Quality of life, Clinical significance.

Accepted on March 24, 2017

\section{Introduction}

Recently, cerebrovascular diseases have some features, such as high recurrence rate, high incidence rate and many complications [1,2]. In dept. of neurosurgery, neurointervention is commonly used for the treatment of them. Cranial neurointervention has many advantages, including little trauma, quick recovery, good clinical curative effect, intuition and reliability. What's more, it can decrease disability rate and mortality of patients [3]. However, in clinical application, the technique of neurointervention still has some risk, and it induces some complication easily, such as bleeding, allergy and epilepsy. Therefore, it is of great significance to strengthen the nursing of cranial neurointervention in clinic [4]. Patients, admitted in the dept. of neurosurgery of our hospital from August 2015 to January 2016, who needed the treatment of cranial neurointervention, were given holistic nursing, making a difference. The report is as follow.

\section{Materials and Methods}

\section{Data}

A total of 138 patients admitted in dept. of neurosurgery in our hospital from August 2015 to January 2016, who needed the treatment of cranial neurointervention, were enrolled, 70 male, 68 female. They were between 28 and 71 years old, and the average age was $43.10 \pm 10.01$. According to the nursing methods, all 138 patients were divided into control group (routine nursing group) and observation group (holistic nursing group), 69 patients a group. The Hunt-Hess grade of all patients was below II grade. In the control group, there were 34 male and 35 female, their age was between 29 and 73, and the average age was $42.13 \pm 10.06$; about Hunt-Hess grade, there were 29 patients with 0 grade, 25 patients with I grade, and 25 patients with II grade. In the observation group, there were 35 male and 34 female, their age was between 31 and 72, and the average age was $41.78 \pm 10.11$; about Hunt-Hess grade, there were 25 patients with 0 grade, 29 patients with I grade, and 25 patients with II grade. In age, sex and Hunt-Hess grade, the patients of both groups had no statistic difference $(\mathrm{P}>0.05)$, having comparability. All participants signed informed consent, and approved by the hospital ethics committee.

\section{Preoperative nursing}

The patients who needed cranial neurointervention underwent various necessary examinations after admission. The patients and their families were told the importance of intervention and points for attention in peroperative period, to dismiss their 
doubts and receive their families' cooperation and understanding [5]. Two days before the operation, the patients practiced defecation on the bed with guidance, preventing uroschesis after operation. Their families were directed to give patients with light diet at $24 \mathrm{~h}$, and fasting for $6 \sim 8$ hours before operation.

\section{Intraoperative nursing}

In the operation, the changes of blood pressure, pulse, blood oxygen saturation and ECG were closely monitored. In this way, abnormal changes of patients could be found and handled timely. In addition, the following conditions were supervised, such as whether the venous channels of patients were unobstructed, whether the patients had headache, aphasia and blurred vision. At the same moment, their upper airway must keep patency.

\section{Postoperative nursing}

After operation, the patients' conciseness, limbs motor and the change of pupil were observed. What's more, whether there were oozing of blood and swelling in puncture point of patients was watched.

\section{Holistic nursing}

The observation group received holistic nursing, which included psychology, diet, posture and complications nursing.

\section{Psychological nursing}

Due to the lack of right understanding about cranial neurointervention in general, patients had fear and anxiety on different levels. Nurses should introduce specific operation process, therapeutic mechanism and points for attention of neurointervention in detail to them before operation. Meanwhile, the nurses should relieve the patients' psychological pressure and eliminate the fear for the operation with psychological knowledge.

\section{Diet nursing}

The patients should take diet control according to their diseases. 6 hours fasting after operation was for those underwent general anesthesia, but those underwent local anesthesia could eat food after operation. The patients were suggested to eat light diet, but no aerogenic, irritative and spicy food, no overeating, to prevent constipation [6]. What's more, they should drink more water to expel contrast agent from the body smoothly.

\section{Posture nursing}

In the operation, the patients needed to keep the supine position, and put their arms on both side of the body. At the same time, in case of arms moved freely, their arms were restrained. After operation, the patients should keep their operated limbs straight, with proper limitation of movement.

\section{Complications nursing}

Nurses should monitor closely the patients' complications after operation, such as bleeding, thrombosis and vagus reflex. If the patients had oozing of blood or hematoma at puncture site of intervention, the nurses should analyze their occurrence causes timely and make relevant nursing measures at the same moment. For the patients with hematuria, bloody stool and disorders of consciousness, the nurses should inform the doctors in time, for fear of internal bleeding or intracranial hemorrhage. For those with coma, hemiplegia and slurred speech, the nurses should tell the clinical doctors timely, in case of femoral arterial thrombosis. For the patients with vasovagal reflex, cooperating with doctor, the nurses should give intravenous dopamine and atropine to them for dilatancy.

\section{Observation indexes}

The occurrence of complications, scores of life quality and patient satisfaction of both groups were observed. The scores of life quality were evaluated by QOL-BREF of WHO, and patient satisfaction questionnaire designed by our department was used to assess the patient satisfaction, of which total scores were 100 . Service attitude, technologies and emergency ability for unexpected events of the nurses were graded comprehensively. Lower than 60 scores was not satisfied, 60 to 90 was generally satisfied, and over 90 was satisfied. (Amount of patients with satisfaction + amount of patients with general satisfaction)/ sum of patients $\times 100 \%=$ satisfaction rate.

\section{Statistical analysis}

The data was processed using statistical analysis software IBM SPSS 19.0. $\bar{x} \pm \mathrm{s}$ was used to analyze the measurement data. $t$ test was used for intra-group comparison and comparison between groups; $\chi^{2}$ test was used for enumeration data. The statistical significance was defined as $\mathrm{P}<0.05$.

\section{Results}

\section{Comparison of scores of quality of life in both groups before and after nursing}

Compared the scores of quality of life in both groups before nursing, there was no statistic difference $(\mathrm{P}>0.05)$; after nursing, the scores of quality of life in the observation group were higher distinctly than the control group, there was statistic difference $(\mathrm{P}<0.05)$ (Table 1).

Table 1. Comparison of scores of quality of life in both groups before and after nursing (scores, $\bar{x} \pm s$ ).

\begin{tabular}{llll}
\hline group & Amounts & $\begin{array}{l}\text { Before treatment and } \\
\text { nursing }\end{array}$ & $\begin{array}{l}\text { After treatment and } \\
\text { nursing }\end{array}$ \\
\hline $\begin{array}{l}\text { Observation } \\
\text { group }\end{array}$ & 69 & $61.19 \pm 2.36$ & $81.03 \pm 5.11$ \\
\hline Control group & 69 & $61.23 \pm 2.38$ & $6.79 \pm 2.35$ \\
\hline$t$ & & 0.36 & 7.03 \\
\hline
\end{tabular}


$p$

0.73

0.00

Notes: compared between two groups before treatment and nursing, $\mathrm{P}>0.05$ compared between two groups after treatment and nursing, $\mathrm{P}<0.05$

\section{Comparison of complications in both groups after nursing}

The incidence rate of complications in the observation group was much higher than the control group, there was statistic difference $(\mathrm{P}<0.05)$ (Table 2)

Table 2. Comparison of the occurrence of complications in two groups after nursing [n(\%)].

\begin{tabular}{|c|c|c|c|c|c|c|c|c|}
\hline Group & Amounts & hematoma & $\begin{array}{l}\text { Oozing of } \\
\text { blood }\end{array}$ & $\begin{array}{l}\text { Urinary } \\
\text { retention }\end{array}$ & $\begin{array}{l}\text { Lower } \operatorname{limb} \\
\text { numbness }\end{array}$ & Hemiplegia & Coma & Incidence rate \\
\hline Observation group & 69 & $0(0)$ & $0(0)$ & $1(1.45)$ & $2(2.90)$ & $(0)$ & $0(0)$ & $3(4.35)$ \\
\hline Control group & 69 & $0(0)$ & $0(0)$ & $2(2.90)$ & $6(8.70)$ & $3(4.35)$ & $1(1.45)$ & $18(26.09)$ \\
\hline$x^{2}$ & 12.64 & & & & & & & \\
\hline$P$ & 0.00 & & & & & & & \\
\hline
\end{tabular}

Notes: compared between two groups after nursing, $\mathrm{P}<0.05$.

\section{Comparison of length of stay and hospitalization expenses of two groups}

The average length of stay of the observation group was much shorter than the control group, there was statistic difference
$(\mathrm{P}<0.05)$ (Table 3). The average hospitalization expenses of the observation group was much lower than the control group, there was statistic difference $(\mathrm{P}<0.05)$ (Table 3$)$.

Table 3. Comparison of length of stay and hospitalization expenses of two groups.

\begin{tabular}{lccc}
\hline Group & amounts & Average length of stay (d) & $\begin{array}{c}\text { Average } \\
\text { (CNY) }\end{array}$ \\
\hline Observation group & 69 & $18.00 \pm 3.13$ & $3678.97 \pm 138.69$ \\
\hline Control group & 69 & $14.01 \pm 1.02$ & $1995.18 \pm 105.87$ \\
\hline$t$ & & 0.36 & 29.64 \\
\hline$P$ & & 0.73 & 0.00
\end{tabular}

Notes: compared between two groups after nursing, $\mathrm{P}<0.05$.

\section{Comparison of patient satisfaction of both groups after nursing}

The satisfaction of the observation group was much higher than the other group, there was statistic difference $(\mathrm{P}<0.05)$ (Table 4).

Table 4. Comparison of patient satisfaction of both groups after nursing [n(\%)].

\begin{tabular}{llllll}
\hline Group & Amounts & $\begin{array}{l}\text { Satisfactio } \\
\mathbf{n}\end{array}$ & $\begin{array}{l}\text { General } \\
\text { satisfaction }\end{array}$ & $\begin{array}{l}\text { Un- } \\
\text { satisfactio } \\
\mathbf{n}\end{array}$ & $\begin{array}{l}\text { Satisfactio } \\
\mathbf{n} \text { rate (\%) }\end{array}$ \\
\hline $\begin{array}{l}\text { Observatio } \\
\text { n group }\end{array}$ & 69 & $35(0)$ & $15(0)$ & $19(1.45)$ & $50(72.46)$ \\
\hline $\begin{array}{l}\text { Control } \\
\text { group }\end{array}$ & 69 & $59(0)$ & $8(0)$ & $2(1.45)$ & $67(97.10)$ \\
\hline
\end{tabular}

\begin{tabular}{ll}
$X^{2}$ & 16.23 \\
$P$ & 16.23 \\
\hline
\end{tabular}

Notes: compared between two groups after nursing, $\mathrm{P}<0.05$

\section{Discussion}

Apart from surgery and medication, intervention therapy is also used for the treatment of cerebrovascular diseases, which are the major disorders affected the health of human being. With the help of computer digital silhouette, cranial neurointervention use mainly catheter technique to diagnosis the lesion affected nervous system and vessels, and then doctors treat the disorder based on the diagnosis [7]. So far, the neurointervention is commonly used in clinic, with a better effect [8]. Limaye US and others [9] point out that with the 
development of intervention materials, intervention shows certain advantages for the treatment of cerebrovascular diseases in prognosis and intraoperative side-injury [10]. Due to the operation of neurointervention is more exquisite and complex, its nursing demands more. In recent years, interventional nursing, as a major part of interventional medicine, has obtained more attention, and the related study has increased gradually. Li Ai'meng and others claim that early rehabilitation of patients with cerebral infarction just focuses on rehabilitation, but no holistic nursing for patients, which is hard to have a good curative effect.Based on routine nursing, the patients with cranial neurointervention are given holistic nursing in the study, make a good difference: the scores of life quality of patients with intervention accepted holistic nursing is much high than those accepted routine nursing; the incidence rate of complications is much lower; the average length of stay is much shorter; the average hospitalization expenses is much less; the patient satisfaction is higher significantly. The holistic nursing in the study includes psychology, diet, posture and complications nursing. Its advantages are as follow: Spirit and mental factors affect the neuro-physiology process of behaviors. Human being is the holism of creature-physiologysociety, and mental factors impact physical and mental health mainly. So ractical and effective psychological intervention before operation can decrease the mental pressure of patients validly, improve prognosis, reduce the incidence rate of complications and increase clinical curative effect $[11,12]$. Psychological nursing before and after cranial neurointervention can eliminate patients' fear and anxiety, preventing high blood pressure in the operation due to nervous, to ensure success of the intervention therapy. Posture nursing can guide patients to turn their posture timely, decreasing their discomfort. Diet nursing can prevent improper diet which impacts smooth recovery of patients after operation. Complications nursing can detect the occurrence of complications in time, make patients receive timely treatment and prevent incidents. In a conclusion, the patient with cranial neurointervention are given holistic nursing based on routine nursing has essential clinical effect, which is worth to be explore. Holistic Nursing Care for Cranial neurointerventional must become habitual Nursing Care for Cranial neurointerventional.

\section{References}

1. Liebeskind DS. Innovative Interventional and imaging registries: precision medicine in cerebrovascular disorders. Interv Neurol 2015; 4: 5-17.
2. You LM, Wu Y. Internal nursing, 4th Ed. The People's Medical Publishing House, Beijing, 2008.

3. Dai LM, Xu F, Chen D. Clinical analysis on complications related to cranial vascular nerve intervention and digging skull operation. Chin J Clin 2016; 8: 1112-1113.

4. Li N. Analysis on nursing for 105 cases of neurointervention. Int J Nurs 2014; 5: 1114-1116.

5. Lin HY, Luo SL, Chen Y. The clinical practice of "mind and body simultaneous nursing" mode in interventional catheter room. J Interv Radiol 2012; 1: 608-610.

6. Deng LM. Clinical observation and nursing on intracranial aneurysm with neurointerventional endovascular embolization therapy. Nursing Prac Res 2015; 12: 70-73.

7. Wang ZHQ, Mao ZQ. Development on diagnosis and treatment of neurointervention. Chin J Neuromed 2011; 5: 433-435.

8. Wang DM, Lu J. Review on new progress of neurointervention: hope and issues coexistence. Chin J Surg 2016; 5: 328-330.

9. Limaye US, Baheti A, SarafR. Endovascular management of giant intracranial aneurysms of posterior circulation. Neurol India 2012; 60: 597-603.

10. Liu JF, Li H, Zhang F. Neurointervention combined with microneurosurgery for patients with ruptured posterior circulation aneurysms and herniation. Chin J Neuromed 2014; 9: 939-941.

11. Li AM, Tan HW, Wang FS. Application of holistic nursing for patients with lacunar infarction. Chin J Modern Nurs 2015; 22: 2678-2679.

12. Cui WY, Jia N, Feng YQ. Mental invention for patients before neurointervention therapy. Med Inf 2011; 1: 4844-4846.

\section{*Correspondence to}

Haijuan Lu

Department of Nursing

Nanyang Central Hospital

PR China 